This item was submitted to Loughborough's Research Repository by the author.

Items in Figshare are protected by copyright, with all rights reserved, unless otherwise indicated.

\title{
New laser technology to determine present weather parameters
}

PLEASE CITE THE PUBLISHED VERSION

PUBLISHER

(C) IOP Publishing

LICENCE

CC BY-NC-ND 4.0

\section{REPOSITORY RECORD}

Ellis, R.A., Andrew P. Sandford, G.E. Jones, James Richards, Jon N. Petzing, and Jeremy M. Coupland. 2019. "New Laser Technology to Determine Present Weather Parameters". figshare.

https://hdl.handle.net/2134/3636. 
This item was submitted to Loughborough's Institutional Repository by the author and is made available under the following Creative Commons Licence conditions.

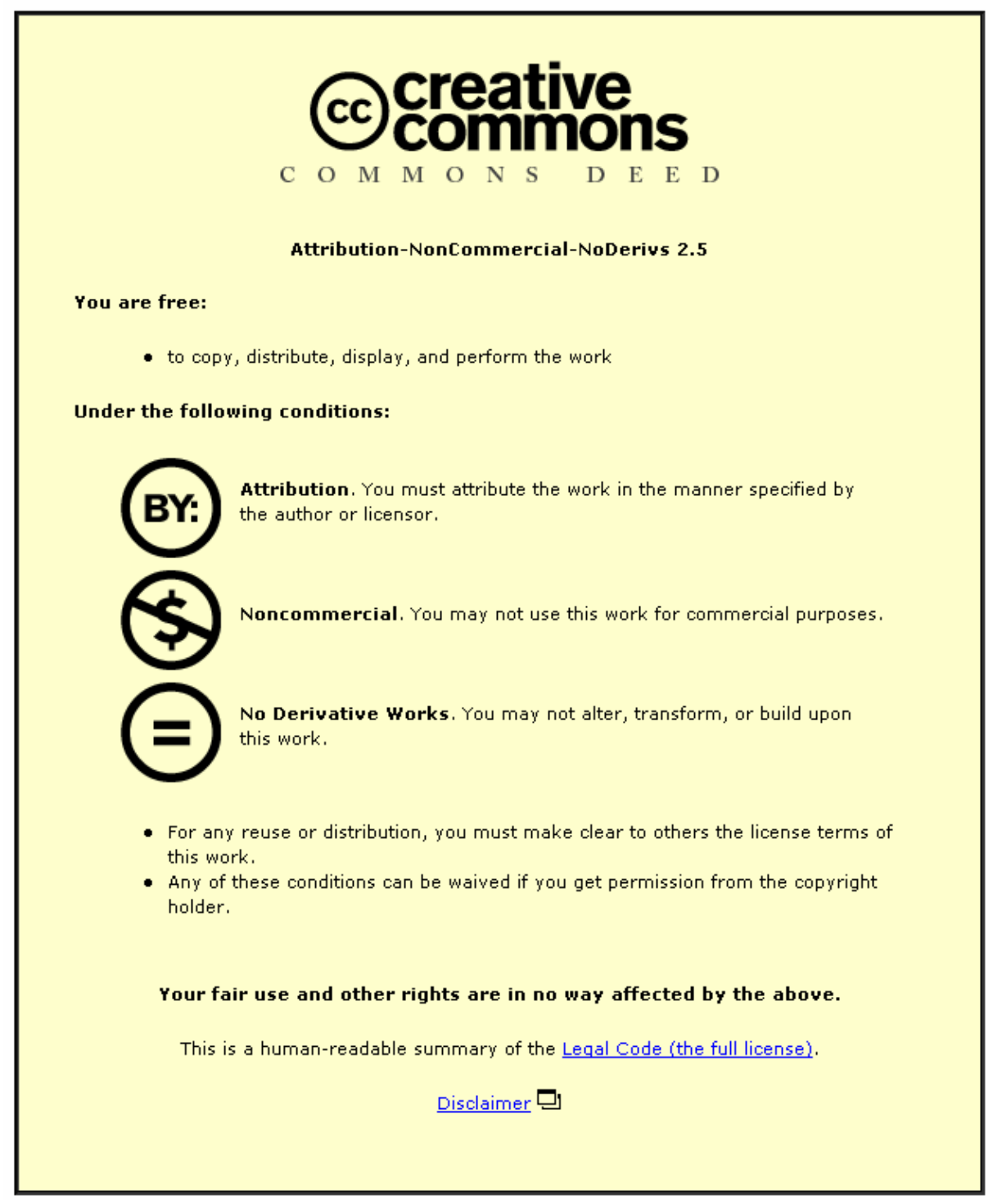

For the full text of this licence, please go to: http://creativecommons.org/licenses/by-nc-nd/2.5/ 


\title{
New laser technology to determine present weather parameters
}

\author{
R A Ellis ${ }^{1}$, A P Sandford ${ }^{1}$, G E Jones ${ }^{1}$, J Richards $^{1}$, J Petzing $^{2}$ and J M Coupland ${ }^{2}$ \\ ${ }^{1}$ Campbell Scientific Ltd., Shepshed, Leicestershire, England. \\ ${ }^{2}$ Loughborough University, Loughborough, Leicestershire, England.
}

(r.ellis@campbellsci.co.uk / Tel: +44 (0) 1509601141 / Fax: +44 (0) 1509 601091)

\begin{abstract}
Present weather sensors are becoming increasingly important as a means to augment networks of automated weather stations and extend the capability of manned observations. The classification of hydrometeors is one of the principal tasks that is addressed by present weather sensors. In this paper we discuss new laser based technology for this purpose. The system improves upon current precipitation monitors by using a derivative of Phase Doppler Anemometry techniques to accurately determine particle speed and size. The instrument is also capable of distinguishing between liquid droplets and solid polycrystalline hydrometeors and can be used to estimate visibility. The incorporation of this technology into a meteorological station with other sensors, such as temperature and relative humidity probes leads to the accurate classification of particle type. The example data shown is taken from tests in Leicestershire, England and Utah, USA and shows the differences between solid and liquid precipitation events.
\end{abstract}

Keywords: Phase Doppler Anemometry, present weather sensor, hydrometeor classification, precipitation measurement, visibility.

\section{Introduction}

The World Meteorological Organization (WMO) defines present weather as a description of the weather phenomena occurring at the time of observation [1]. The description is based on weather perceived by a human observer according to a standard scale of events defined in the WMO Manual on Codes [2] and by its nature is largely subjective. Although not as capable as human observers, automated present weather sensors provide an objective classification and 
provide a cost effective way to implement sensor networks that reach into remote and hostile locations.

One of the principal tasks of PWS instrumentation is the classification of hydrometeors into rain, hail, sleet and snow etc. Commercial PWS instrumentation generally distinguishes precipitation types using a combination of measurements from light scatter or light occlusion sensors with other measurements of temperature, relative humidity and wetness etc. The Vaisala PWD22 and Biral VPF-730 are light scatter sensors that are capable of measuring the scintillation observed at one or more angles as individual hydrometeors pass through a beam of light. In essence, visibility is derived from the time averaged data, an estimate of particle size can be made from the amplitude of each scintillation signal and terminal velocity can be estimated from the duration of the scintillation or transit time. It is noted however, that the size and terminal velocity relationships are only approximate, and vary considerably if hydrometeors fall obliquely through the beam or have differing scattering characteristics.

Light beam occlusion type instruments, such as the OTT Parsivel and the Thies Clima Laser Precipitation Monitor use a horizontal light sheet and consequently avoid many of the problems of oblique incidence. Rather than detect scattered light, they measure the amplitude and duration of the light occluded from the sheet as hydrometeors pass through to obtain the particle size and terminal velocity respectively. In this way a relatively large signal is produced, but small temporal variations in the light sheet intensity makes visibility estimation difficult and problems are encountered once again for hydrometeors of varying scattering efficiencies.

In this paper the classification of hydrometeors according to their size and terminal velocity is considered from first principles with particular reference to its value in PWS applications. New instrumentation based on Phase Doppler Anemometry (PDA) is then proposed to accurately measure these characteristics. Finally we show how solid and liquid precipitation can be distinguished, and how visibility can be estimated from a signal acquired in this way.

\section{Classification of hydrometeors according to size and terminal velocity}

In the absence of up-currents, the size and terminal velocity of rain and drizzle droplets are very well correlated. The relationship was studied experimentally by Laws in 1941 [3] and Gunn and Kinzer in 1949 [4] and given mathematical form in the model published by Best [5]. Best concludes that the terminal velocity, $v$, can be defined in three regions by separate 
equations. For droplets with diameter, $\mathrm{d}_{\mathrm{p}}<5 \times 10^{-5} \mathrm{~m}$, the terminal velocity results from the drag governed by Stokes Law such that,

$$
\mathrm{v}=\mathrm{Ad}_{\mathrm{p}}^{2}
$$

Where $\mathrm{A}$ is a constant equal to $3.04 \times 10^{7} \mathrm{~m}^{-1} \mathrm{~s}^{-1}$ (at sea level in non-tropic regions). The behaviour of large droplets is more complex as the shape departs from spherical $[6,7,8]$ and internal flows are initiated within the droplet [9]. If the constant, $d_{p}$, is interpreted as the equivalent diameter of a spherical droplet of equal volume, for larger droplets, Best suggests that the terminal velocity is described by,

$$
v=B\left\{1-\exp \left[-\left(d_{p} / a\right)^{n}\right]\right\}
$$

For droplet diameters in the region $5 \times 10^{-5} \mathrm{~m}<\mathrm{d}_{\mathrm{p}}<3 \times 10^{-4} \mathrm{~m}$ the constants $\mathrm{B}=1.91 \mathrm{~ms}^{-1}, \mathrm{a}=$ $3.16 \times 10^{-4} \mathrm{~m}$ and the power $\mathrm{n}=1.754$. For droplet diameters $\mathrm{d}_{\mathrm{p}}>0.3 \times 10^{-4} \mathrm{~m}$ Best proposes the constants $\mathrm{B}=9.32 \mathrm{~ms}^{-1}, \mathrm{a}=1.77 \times 10^{-3} \mathrm{~m}$ and the power $\mathrm{n}=1.147$.

These equations agree well (better than 4\%) with the experimental findings of Laws and Gunn and Kinzer. Together they define the trend illustrated in figure 1 which we refer to as the rain line. As we will show in section 3.1, hydrometeors corresponding to rain and drizzle events can be identified by their proximity to the rain line.

In contrast, solid precipitation shows quite different behaviour. In this case the definition of size becomes an issue in itself given the complex structures found in snow or the varying shape parameters required to classify ice pellets, hail, graupel and other solid forms of precipitation. The introduction of the $2 \mathrm{D}$ video disdrometer, an instrument comprising of two line-scan cameras that image particles as shadows, has provided greater insight into the nature of solid precipitation measurement. Of particular interest here are studies that correlate a dimension (or shape) characteristic with terminal velocity. Hanesch et al. [10] demonstrate that the terminal velocity correlates more closely with the height of particle (i.e. the dimension perpendicular to the motion) than other parameters, such as maximum particle diameter, the diameter of a circle with the same area as the shadow and the mean of two orthogonal extensions (height and width). Although combinations of the various shape parameters give improved velocity-shape relationships, it is clear from this study that there is a very high variability in terminal velocity for particles with the same size due to the vast 
array of shapes and particle densities possible. Nevertheless for the case of solid hydrometeors we will interpret the particle diameter, $d_{p}$, as the height (vertical dimension as it falls). For the case of unrimed snow crystals, Bohm [11] suggests that the terminal velocity is in the region bounded by the following power law equations,

$$
1.5 \mathrm{~d}_{\mathrm{p}}^{0.11}<\mathrm{v}<3.6 \mathrm{~d}_{\mathrm{p}}^{0.16}
$$

As the degree of riming increases so does the terminal velocity. Schefold [12] showed that for particles with degrees of riming from very light to heavy falls in the region bounded by the power law equations,

$$
3.5 \mathrm{~d}_{\mathrm{p}}^{0.2}<\mathrm{v}<82.0 \mathrm{~d}_{\mathrm{p}}^{0.6}
$$

Graupel, was defined by Locatelli and Hobbs [13] as extremely heavily rimed particles and its terminal velocity is given by,

$$
\mathrm{v}=125 \mathrm{~d}_{\mathrm{p}}^{0.66}
$$

Finally, studies of hail show more consistent behaviour although the density and shape are not as well defined as for rain $[14,15,16]$. From these studies it can be concluded that the velocity is approximately bounded by the power law equations,

$$
110 \mathrm{~d}_{\mathrm{p}}^{0.5}<\mathrm{v}<125 \mathrm{~d}_{\mathrm{p}}^{0.5}
$$

though Knight and Heymsfield [16] showed that soaked hailstones are outside of this range and fall with velocities closer to rain at particle diameters greater than $2 \mathrm{~mm}$. This is most likely due to the liquid-air interface having some degree of molecular movement if not the internal circulation observed in rain. The liquid-air interface may account for rain falling faster than solid hail particles up to diameters of approximately $5 \mathrm{~mm}$ even with the drag increase due to liquid particle distortion.

Since these studies fit curves to real data and small sized particles appear to be sparsely detected in most cases, the curves at the lower end must be treated with some caution. 
The solid precipitation distributions together with the rain line are shown in figure 1. In the case of snow, only the lower boundary of unrimed crystals and upper boundary of heavily rimed particles are shown for clarity.

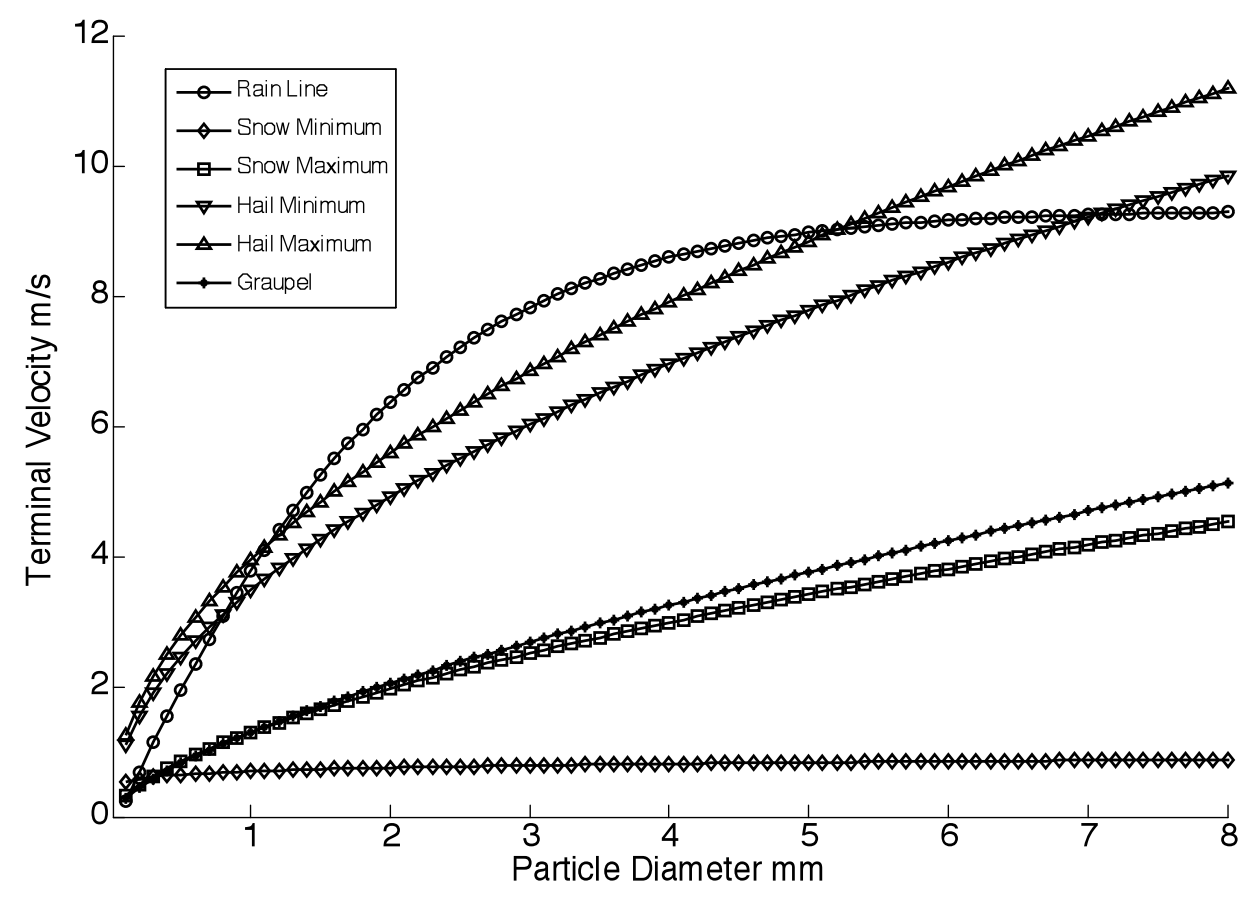

Figure 1. Snow, hail, graupel and rain distributions for particles at terminal velocity.

It can be concluded from the literature review that the distributions that define the precipitation type are well separated over most of the region, however, accurate measurements are required to separate hydrometeors of low velocity (and small size). In the following section we describe new instrumentation based on Phase Doppler Anemometry (PDA) with this capability.

\section{Phase Doppler Measurements of Droplet Size and Velocity}

Laser Doppler Anemometry (LDA) was first demonstrated by Yeh and Cummins in 1964 as a non-intrusive method to measure the velocity of particles [17]. In essence modern LDA equipment measures the frequency of the scattered intensity collected as a particle traverses a series of interference fringes generated by crossed laser beams [18]. Shortly after the work of Yeh and Cummins, it was realised that for a single, spherical particle, the phase of the signal collected at a given angle depends on the size of the particle [19]. However, to avoid the ambiguity caused by phase variations greater than $2 \pi$ radians and to provide an independent 
sphericity check, a third detector is used in most modern equipment in the configuration that is usually referred to as the standard Phase Doppler Anemometry (PDA) arrangement [18].

PDA is most often used to size particles in the range 1-200 microns and few papers consider its use outside this range. One reason for this is that the generation of a suitable set of large scale interference fringes requires that the laser beams cross at a small angle (approximately $0.5 \mathrm{mrad}$ for $1 \mathrm{~mm}$ fringe spacing) and this results in a poorly defined measurement volume. According to Mie scattering theory, particle size can be estimated from the absolute intensity of the scattered signal and/or its depth of modulation using a standard PDA configuration [20]. For the case of particles with a diameter larger than the dimension of the measurement volume, the size can also be deduced from the transit time obtained from a signal obtained at glancing angle [21], however, great care must be taken to account for particle trajectory [22].

A technique to measure the size of large droplets that is very closely related to PDA was introduced by Nakatani and Oshio [23]. The technique derives particle velocity from the time separation between pulses in the scattered intensity as the particle falls through two or more light sheets. Particle size is derived from the relative time delay between signals received at different scattering angles [24]. For the case of transparent droplets or particles, refractive index can also be deduced from the relative time delay between refracted and reflected contributions (separated in the time domain or by sensors at appropriate scattering angles) [25]. These methods are collectively referred to as the Pulse Displacement Technique (PDT) since time delay rather than phase is measured. For a quasi-periodic signal collected as the droplet falls through either a finite set of interference fringes or light sheets it is noted that time delay and phase measurements are proportional to each other and consequently PDA and PDT are essentially equivalent.

The instrument we have designed as a PWS consists of a transmitter and two detector units as shown in side and plan views of figures $2 a$ ) and $2 b$ ) respectively. The transmitter outputs structured light that is essentially a set of four parallel, horizontal light sheets spaced at 0.8 $\mathrm{mm}$ intervals. The detectors receive light from a well defined region of the light sheet and at well defined angles. In our instrument, detector A receives light that is scattered through an angle of 20 degrees in the vertical plane while detector B receives light that is scattered through an angle of 20 degrees in the horizontal plane. The relative position of the detectors is chosen such that they receive light from the measurement region defined by the overlap area, $\phi$. 

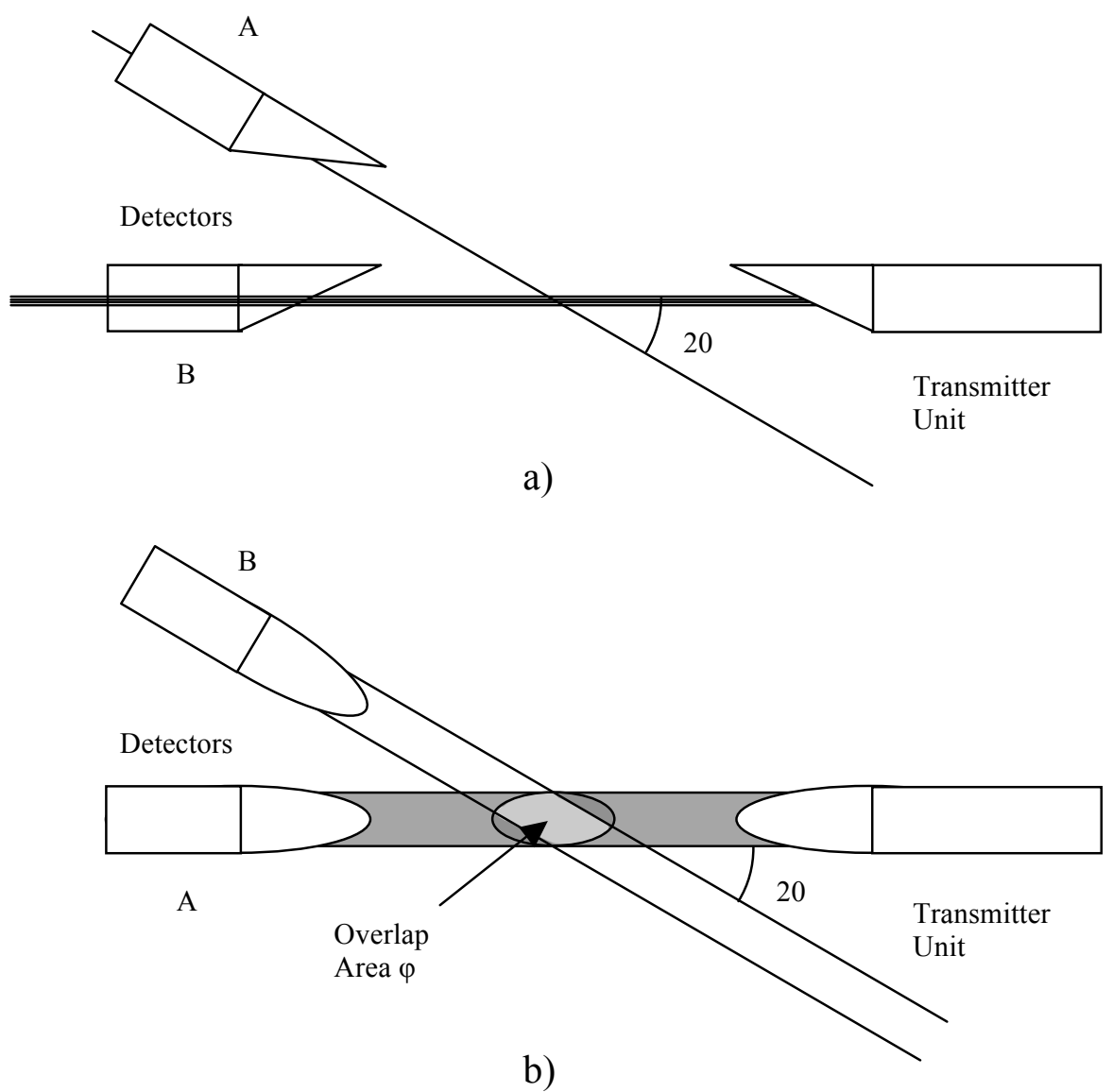

Figure 2. Transmitter and detector arrangement in a) side view and b) plan view.

In general, light is scattered from hydrometeors by mechanisms of reflection, refraction, and diffraction. The relative contributions of these measurements depend on the nature of the hydrometeors. For this reason we consider the measurement of terminal velocity and size for liquid droplets and solid (polycrystalline) hydrometeors separately in the following sections. We then consider estimation of visibility using this instrumentation.

\subsection{Measurement of liquid droplets}

Analysis shows that for spherical water droplets with sizes between 0.1 and10 $\mathrm{mm}$ and at the moderate angles used here, reflection and diffraction are insignificant and refraction is the dominant scattering mechanism [19]. The effect of refraction from a spherical water droplet can be found using a ray trace analysis. 


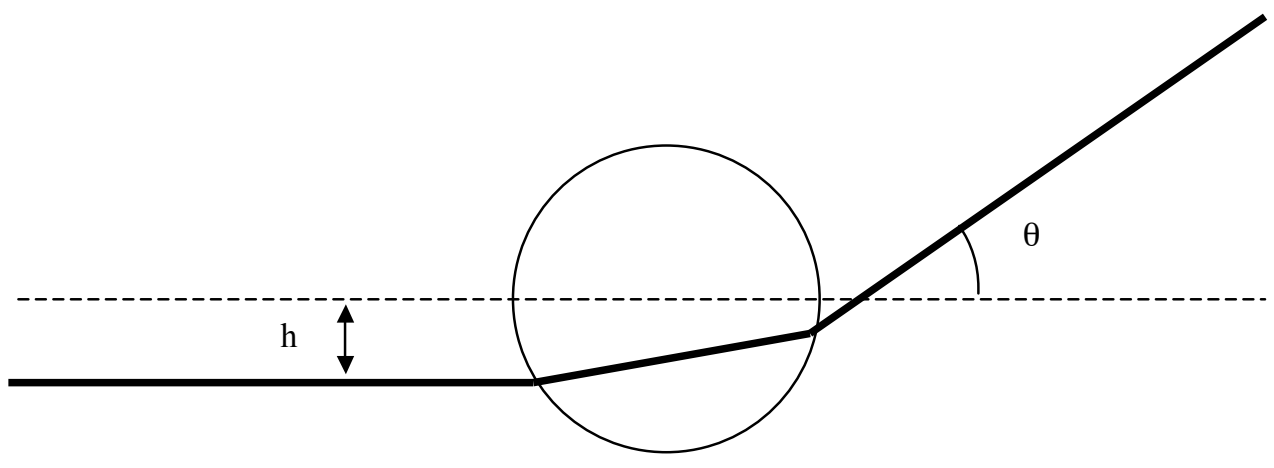

Figure 3. The effect of refraction from a spherical water droplet.

With reference to figure 3, for the case of a spherical droplet of radius $r$, it is straightforward to show that a ray that is parallel but offset a distance, $\mathrm{h}$, from the chief ray deviates through an angle, $\theta$, given by,

$$
\theta=2\left[\sin ^{-1}\left(\frac{h}{r}\right)-\sin ^{-1}\left(\frac{h}{n r}\right)\right]
$$

where $\mathrm{n}$ is the refractive index. After some algebraic manipulation this equation can be rewritten to give the offset required of a ray such that it is recorded by a detector aligned at the angle $\theta$,

$$
h=\frac{\mathrm{rn} \sin (\theta / 2)}{\sqrt{1+\mathrm{n}^{2}-2 \mathrm{n} \cos (\theta / 2)}}
$$

Consequently, if a droplet is falling through the measurement region of the instrument, detector A will receive light scattered from a given light sheet when the droplet has an appropriate offset. As the droplet falls through the light sheet, equation 8 . will be satisfied for each light sheet in turn, giving rise to a quasi-periodic signal. If the light sheets are separated by, $\mathrm{s}$, the droplet velocity, $\mathrm{v}$, can be found by measuring the time delay, $\Delta \mathrm{t}_{\mathrm{A}}$, at detector $\mathrm{A}$ (or equivalently $\Delta \mathrm{t}_{\mathrm{B}}$, at detector $\mathrm{B}$ ) such that,

$$
\mathrm{v}=\frac{\mathrm{s}}{\Delta \mathrm{t}_{\mathrm{A}}}=\frac{\mathrm{s}}{\Delta \mathrm{t}_{\mathrm{B}}}
$$


It is also evident from equation 8 that detectors mounted at different angles will receive light that is scattered from each light sheet at slightly different times. In the configuration illustrated in figure 2, detector A receives light when the droplet has an offset appropriate to its angle whilst detector $B$ receives the same signal when there is no offset since it is in the horizontal plane $(\theta=0)$. In practice this means that detector A receives the signal slightly before detector $\mathrm{B}$. If the droplet is moving through the light sheet at velocity $\mathrm{v}$, the corresponding time delay, $\Delta \mathrm{t}_{\mathrm{AB}}$, between the signals recorded by detectors $\mathrm{A}$ and $\mathrm{B}$, is given by,

$$
\Delta \mathrm{t}_{\mathrm{AB}}=\frac{\mathrm{h}}{\mathrm{V}}
$$

Substituting equation 8 we have,

$$
? \mathrm{t}_{\mathrm{AB}}=\frac{\mathrm{rn} \sin (\theta / 2)}{\mathrm{v} \sqrt{1+\mathrm{n}^{2}-2 \mathrm{n} \cos (\theta / 2)}}
$$

For a given particle velocity, the time delay relative to a detector in the horizontal plane is a linear function of particle radius. For the system shown in figure 2 it follows from equations 7-11 that the particle diameter is given by,

$$
\mathrm{d}_{\mathrm{p}}=2 \mathrm{r}=\frac{2 \mathrm{~s} \Delta \mathrm{t}_{\mathrm{AB}} \sqrt{1+\mathrm{n}^{2}-2 \mathrm{n} \cos \left(\theta_{\mathrm{D}} / 2\right)}}{\Delta \mathrm{t}_{\mathrm{A}} \mathrm{n} \sin \left(\theta_{\mathrm{D}} / 2\right)}=\frac{2 \mathrm{~s} \Delta \mathrm{t}_{\mathrm{AB}} \sqrt{1+\mathrm{n}^{2}-2 \mathrm{n} \cos \left(\theta_{\mathrm{D}} / 2\right)}}{\Delta \mathrm{t}_{\mathrm{B}} \mathrm{n} \sin \left(\theta_{\mathrm{D}} / 2\right)}
$$

where $\theta_{\mathrm{D}}$ is the angle subtended by detector A from horizontal. It is clear from equation 12 that the radius is proportional to the ratio of the two time delays, $\Delta \mathrm{t}_{\mathrm{AB}} / \Delta \mathrm{t}_{\mathrm{A}}$.

Typical signals, $I_{A}(t)$ and $I_{B}(t)$, output from detectors $A$ and $B$ respectively, are shown in figures $4 \mathrm{a}$ ) and $4 \mathrm{~b}$ ). It is noted that the signals (or Doppler bursts) are quasi-periodic and that detector A receives the signal slightly before detector B as expected. In this case the time delays, $\Delta \mathrm{t}_{\mathrm{AB}}$ and $\Delta \mathrm{t}_{\mathrm{A}}$ can be deduced from the cross-correlation, $\mathrm{R}_{\mathrm{AB}}(\mathrm{t})$ of these signals defined by,

$$
R_{A B}(t)=\int_{-\infty}^{\infty} I_{A}(\varepsilon) I_{B}(\varepsilon-t) d \varepsilon
$$


Figure 4c) shows the cross-correlation corresponding to the Doppler bursts shown in figures $4 a)$ and $4 b$ ). It can be seen that the cross-correlation is also quasi-periodic with a period similar to that of $\mathrm{I}_{A}(\mathrm{t})$ and $\mathrm{I}_{\mathrm{B}}(\mathrm{t})$. The position of the largest peak (relative to the origin) gives the time delay, $\Delta \mathrm{t}_{\mathrm{AB}}$, while the period gives a measure of the time delay, $\Delta \mathrm{t}_{\mathrm{A}}$ (or equivalently $\left.\Delta \mathrm{t}_{\mathrm{B}}\right)$ as shown.

Although the analysis presented here defines the particle diameter in terms of time delay, $\Delta \mathrm{t}_{\mathrm{AB}}$, rather than a phase angle as is usual in PDA, the principle of operation is the same. It is clear that the relative phase of the dominant frequency in the signals, $I_{A}(t)$ and $I_{B}(t)$, is given by, $2 \pi \Delta t_{A B} / \Delta t_{A}$. As a point of interest, however, it is noted that the relative time delay, $\Delta t_{A B}$, can be greater than the period, $\Delta t_{A}$, and consequently, phase shifts that are greater than $2 \pi$ radians can be measured without ambiguity. It is apparent from figure 4 that this is only possible if there is a clearly identifiable peak in the cross-correlation. In a more typical crossbeam PDA system there are many more fringes in the probe volume and the corresponding Doppler bursts, $\mathrm{I}_{\mathrm{A}}(\mathrm{t})$ and $\mathrm{I}_{\mathrm{B}}(\mathrm{t})$, would contain many more cycles. As a consequence the crosscorrelation analysis would yield a signal with many peaks (or cycles) of similar amplitude and it would be difficult to identify the largest peak especially when noise was present. For this reason commercial PDA equipment usually makes use of three detectors set at appropriate angles [3] whereas only two detectors are necessary here.
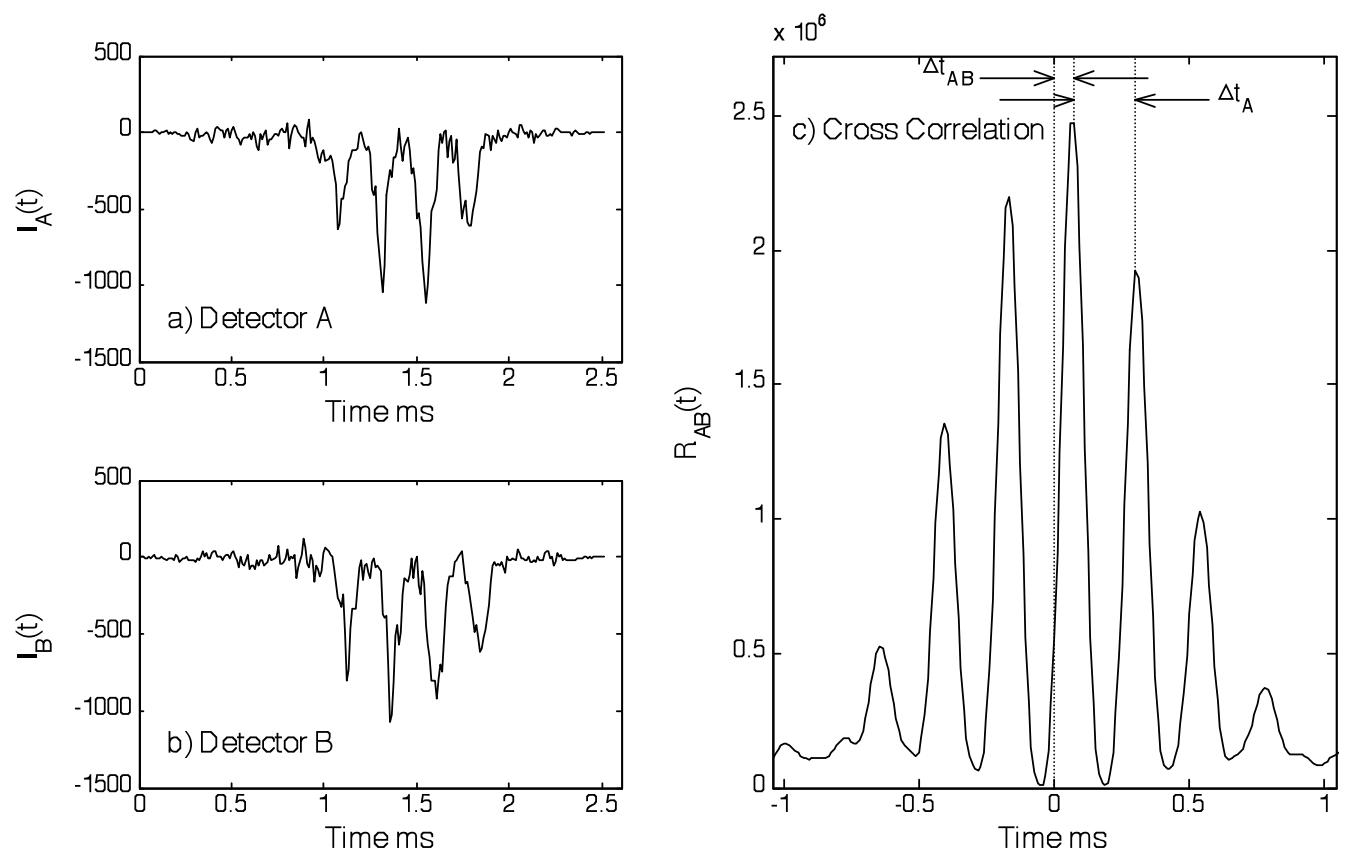

Figure 4. Typical rain signal showing a) detector A, b) detector B and c) cross correlation. 
The analysis presented above assumes that droplets are spherical. In practice larger drops $(\mathrm{d}>$ $2 \mathrm{~mm}$ ) deviate quite dramatically from this form, becoming progressively more oblate. Several studies of drop shape been made $[6,7,8]$ and can be summarised in the empirical relationship defined by Beard and Chuang [8].

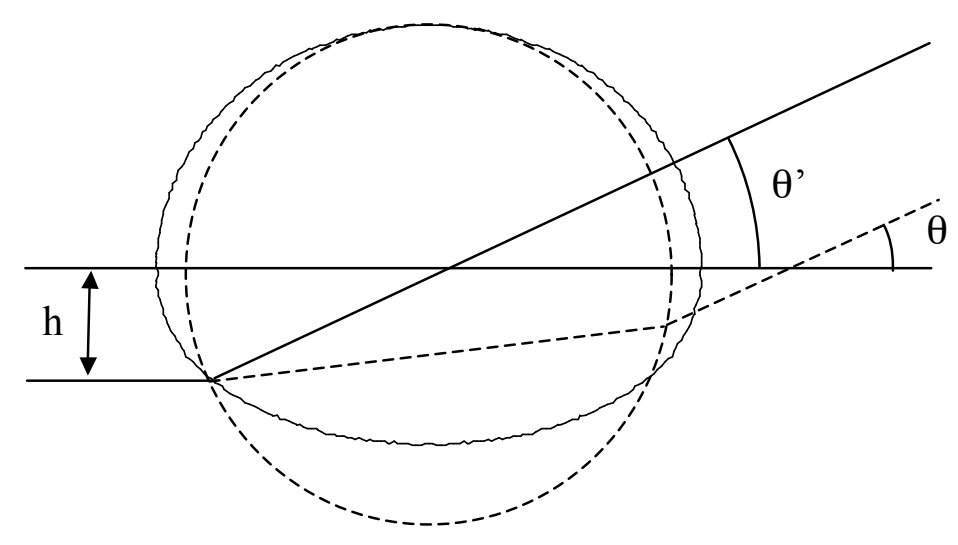

Figure 5. Beard and Chuang model of a $4 \mathrm{~mm}$ rain drop.

Figure 5 shows the shape of a spherical $4 \mathrm{~mm}$ droplet (dotted outline) together with an oblate droplet of equal volume predicted by this model (solid outline). It is noted that as the drop becomes more oblate the optical power of the surfaces becomes greater but their separation also increases and this reduces the total power of the lens. For small deviations from spherical these two effects almost compensate for each other. In this case it can be seen that rays with an equal offset, $h$, emerge at approximately equal angles $\left(\theta^{\prime}=\theta\right)$. Consequently, to a good approximation, the measured drop diameters can be interpreted as the equivalent diameter of a spherical particle.

\subsection{Measurement of solid hydrometeors}

Solid or mixed solid/liquid hydrometeors (snow, sleet, hail etc.) are generally non-spherical and are usually multi-faceted and polycrystalline in nature. As such the analysis presented in the previous section is inapplicable. Solid hydrometeors can be considered as a collection of randomly distributed scattering sites as illustrated in figure 6 . 


\section{Light scattered}

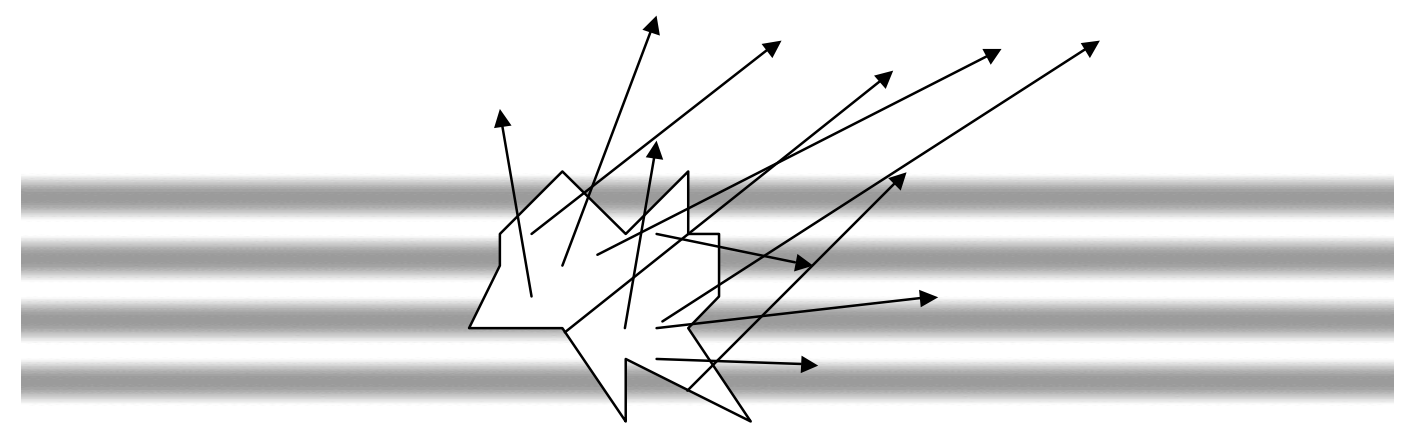

Light sheets

Figure 6. Random scattering for polycrystalline particles.

Since the light sheets are coherent, the scattered light interferes to add constructively or destructively at a given angle according to the phase relationship defined by the relative positions of the dominant scattering sites. The illumination is a quasi-periodic structure, however, and consequently the same scattering sites with the same phase relationship will produce (approximately) the same signal as they pass through each of the light sheets. Hence there will be periodicity (although with reduced modulation depth) in the detector signal collected at a given angle and a valid measurement of velocity can be made as in the case of liquid droplets. It is noted however, that constructive interference at one angle does not mean constructive interference at another and no fixed relationship occurs between the phases of the signals collected at different angles. Consequently if the methods of PDA specified in the previous section, are used to estimate particle size a random answer will result. Typical signals for snow are shown in figures $7 \mathrm{a}$ ) and $7 \mathrm{~b}$ ) and the resulting correlation shown in $7 \mathrm{c}$ ) Note that for this case the correlation peak corresponds to a negative delay and hence a negative particle size would be estimated by PDA. 

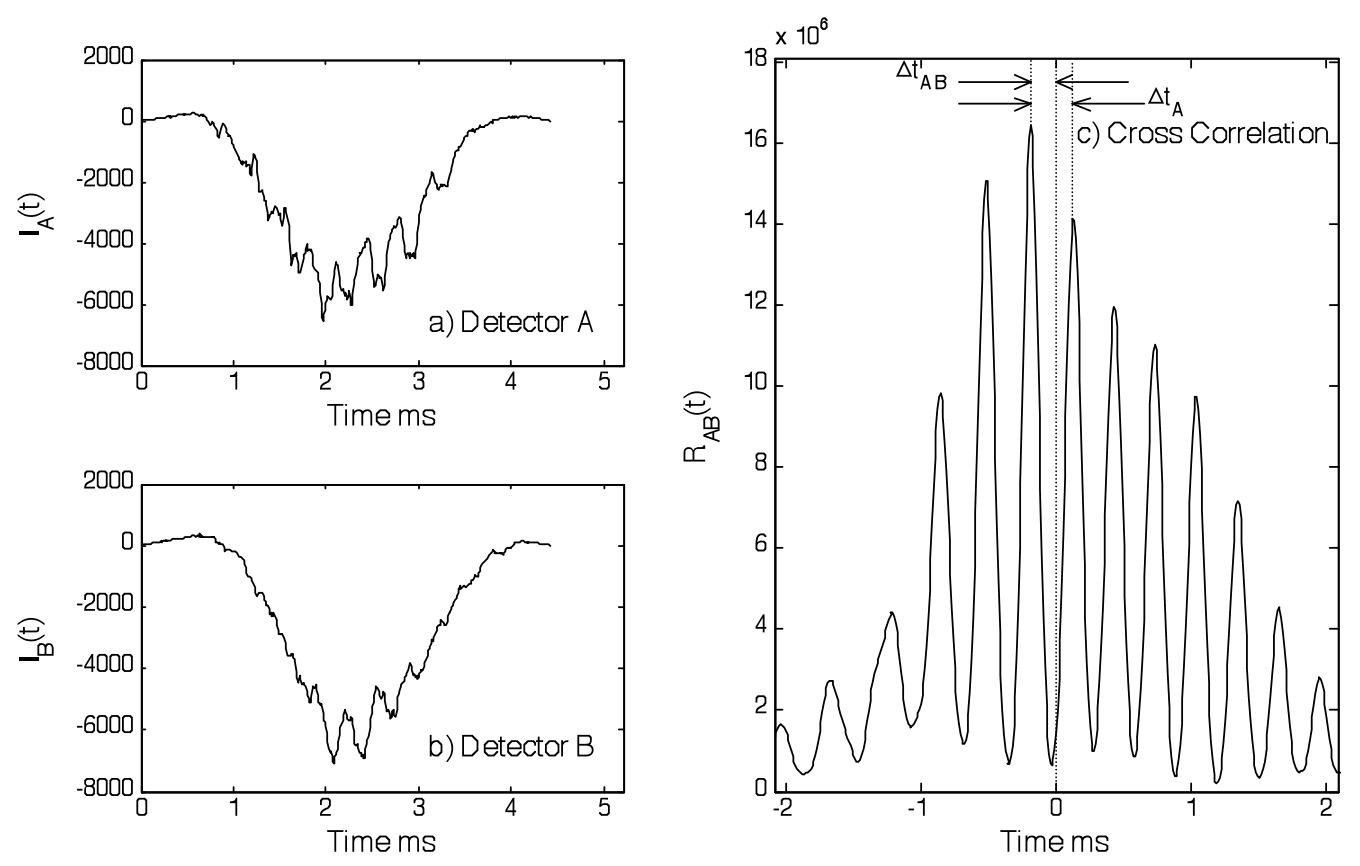

Figure 7. Typical snow signal showing a) detector A, b) detector B and c) cross correlation.

These characteristics provide a way to distinguish between liquid droplets and solid hydrometeors.

Finally it is noted that since the velocity can be measured, the size (height) of solid hydrometeors can be estimated from transit time measurements. For convenience, it is assumed that the envelope of the Doppler burst is Gaussian with a width, $\Delta \mathrm{t}_{\mathrm{p}}$, measured at the $1 / \mathrm{e}^{2}$ point and the envelope of the light sheet intensity distribution is Gaussian with a total thickness $\mathrm{T}$, measured in a similar manner. With these assumptions it is straightforward to show that the particle diameter is given by,

$$
\mathrm{d}_{\mathrm{p}}=\sqrt{\left(\mathrm{v} \Delta \mathrm{t}_{\mathrm{p}}\right)^{2}-\mathrm{T}^{2}}
$$

For data shown in figure 7 for a relatively large (approximately $5 \mathrm{~mm}$ ) snow particle it is observed that approximately 9 cycles are apparent in the detector signals. In this case $v \Delta \mathrm{t}_{\mathrm{p}}$ is significantly greater than $\mathrm{T}$ and equation 14 will provide a good estimate of size. However it is clear that this method does not produce accurate estimates when the particle size is less than the light sheet thickness and in practice an uncertainty of around $\pm 0.5 \mathrm{~mm}$ is typical. 


\subsection{Visibility measurement}

The basic geometry of figure 2 is similar in many respects to those found in conventional visibility sensors. Since the detectors can be used to measure the mean intensity of the light scattered in a given direction, an estimate of the scattering coefficient can be made. In the present instrument it is assumed that the mean intensity, $I_{s}$, collected by the detectors is directly proportional to the scattering coefficient, $\mathrm{k}_{\mathrm{s}}$, averaged over the same interval. Furthermore it is assumed that absorption has a negligible effect on visibility. In this case the visibility for a $5 \%$ detection threshold, $\mathrm{R}_{\mathrm{m}}$, can be written,

$$
\mathrm{R}_{\mathrm{m}}=2.996 / \mathrm{k}_{\mathrm{s}}
$$

For our present instrument we conclude,

$$
\mathrm{R}_{\mathrm{m}}=\mathrm{R}_{0} / \mathrm{I}_{\mathrm{s}}
$$

where the constant $R_{o}$ is determined from comparison with human observation. This method is found to work well in conditions of mist and fog where the hydrometeors are small and disperse. However, when larger droplets are present, information concerning the number and type of droplets can be used to improve the visibility estimate. This method is beyond the scope of the present paper.

\section{Experimental Results}

Three present weather sensors (PWS) have been constructed according to the configuration in figure 2. Two sensors are based at Campbell Scientific Ltd. in Shepshed, Leicestershire, UK the other is located at Campbell Scientific Inc., Utah, USA. These instruments use a high speed digital signal processor (DSP) to analyse the data. The raw data and results can be collected remotely using a modem link. The instruments have been collecting data for approximately 10 months. In the following sections some typical results concerning the size, velocity and visibility measurements are illustrated.

\subsection{Size and velocity measurements during a rain event}

Figure 8 shows data collected using the PWS sizing method, plotted over the rain line, during a 16 hour period covering a number of light rain events that occurred on $5^{\text {th }}$ July 2005 in 
Shepshed. In the 16 hour period over 18000 hydrometeors were counted with peak count rates of approximately 10 counts per second observed and a peak rain rate of approximately 2 $\mathrm{mmh}^{-1}$ (hourly accumulations). Many of the particles were of sizes corresponding to drizzle $(<0.5 \mathrm{~mm}$ diameter).

Few particles with measured diameters greater than $3 \mathrm{~mm}$ or velocities greater than $7 \mathrm{~ms}^{-1}$ were measured in this event. This is because droplets of this size and greater are unstable and break into smaller droplets and atmospheric conditions were more conducive to the production of smaller particles. It is thought that the few instances of fast droplets above that expected are secondary droplets from dissociated larger drops. The minimum particle size set to be measured was $0.2 \mathrm{~mm}$ during this event.

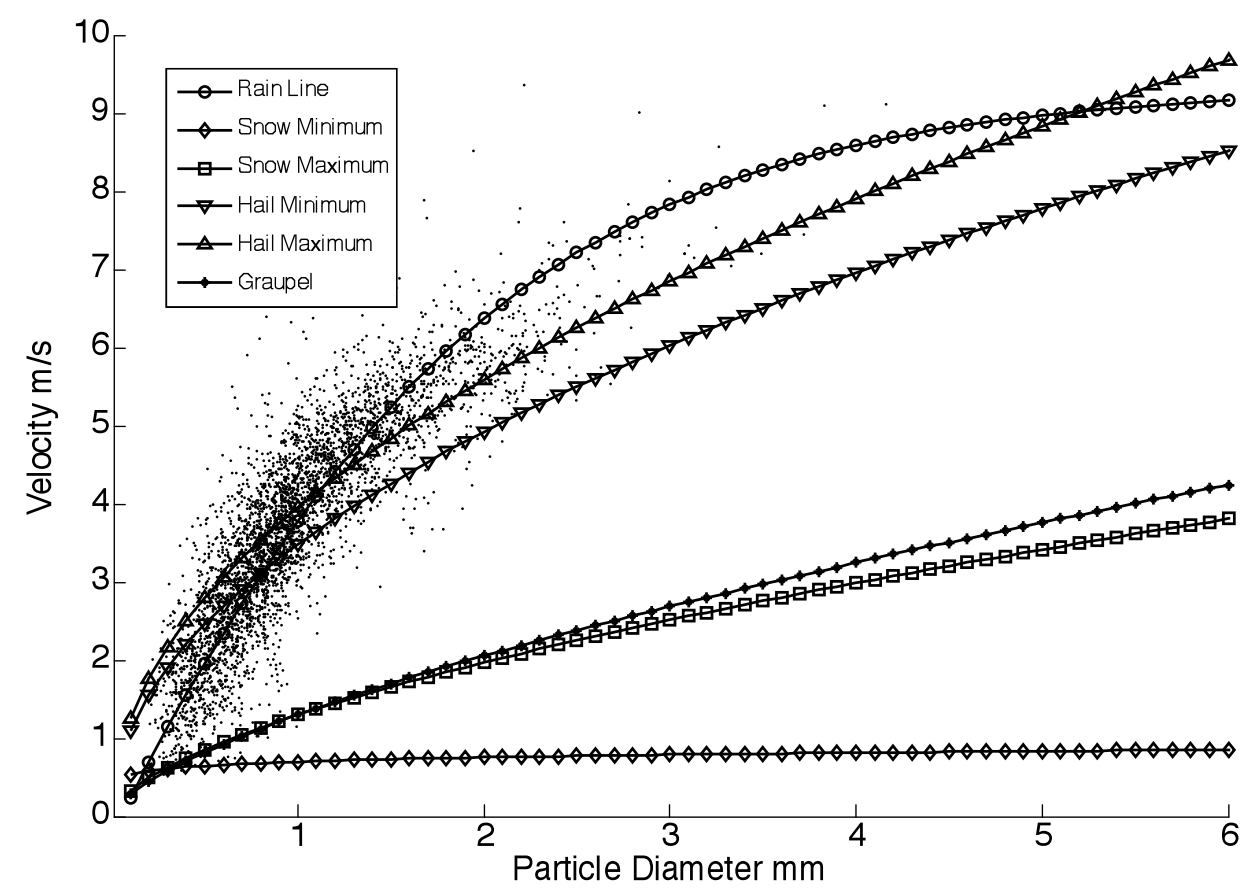

Figure 8. PWS size and velocity measurements in a rain event.

\subsection{Size and velocity measurements during a snow event}

Figure 9 shows data collected using the PWS sizing method during a short snow event on $22^{\text {nd }}$ February 2005 in Shepshed, England. The rain line and the bands for snow, graupel and hail as defined in equations 3, 4, 5 and 6 are shown. As mentioned previously the size measurements are meaningless in this case since no set phase or time delay exists for 
polycrystalline particulates. It can be seen however, that although random in nature the most likely size measurement is zero.

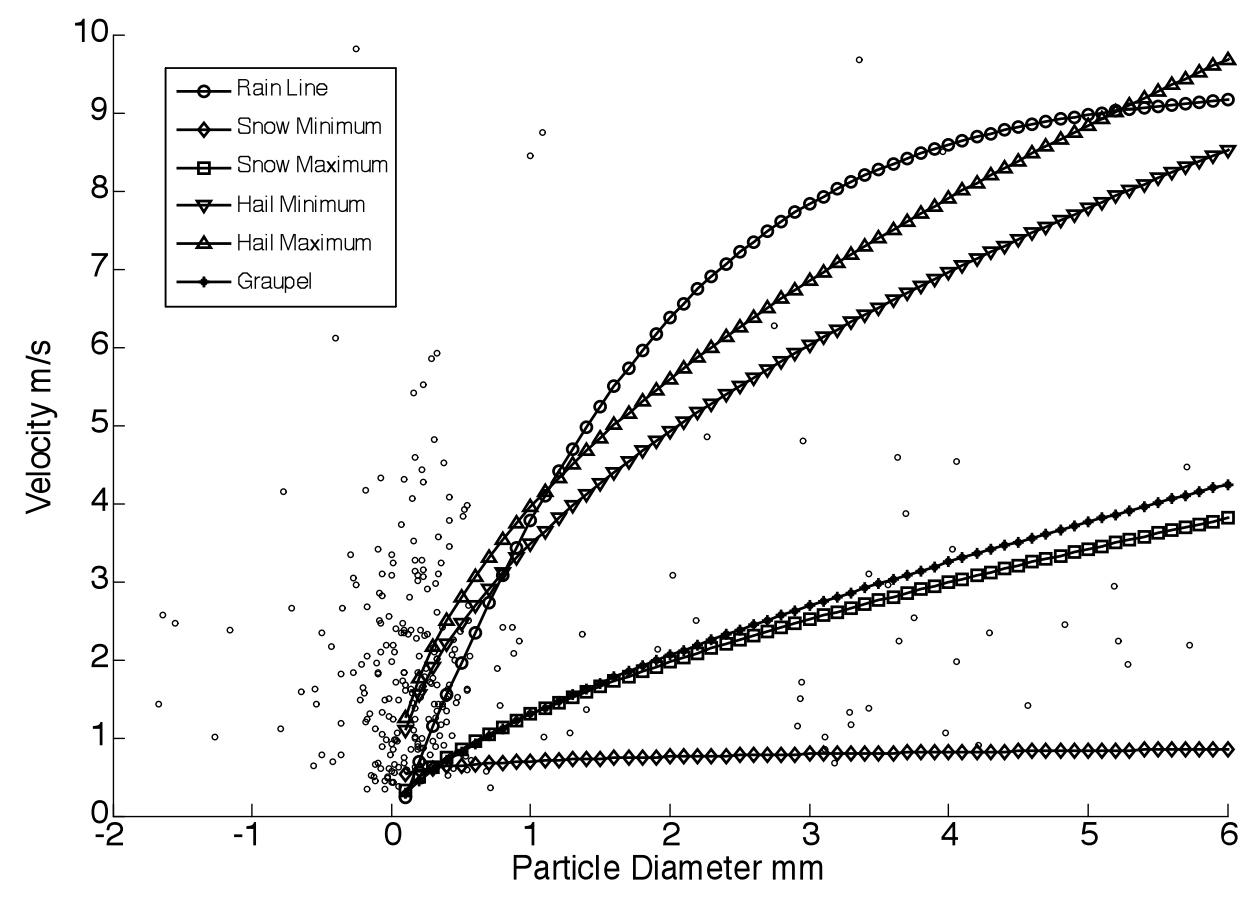

Figure 9. PWS size and velocity measurements in a snow event.

Figure 10 shows the same event with size measurements derived from transit delay measurements as defined in equation 14. In this case a quite different distribution is observed. It is this difference that indicates solid hydrometeors. 


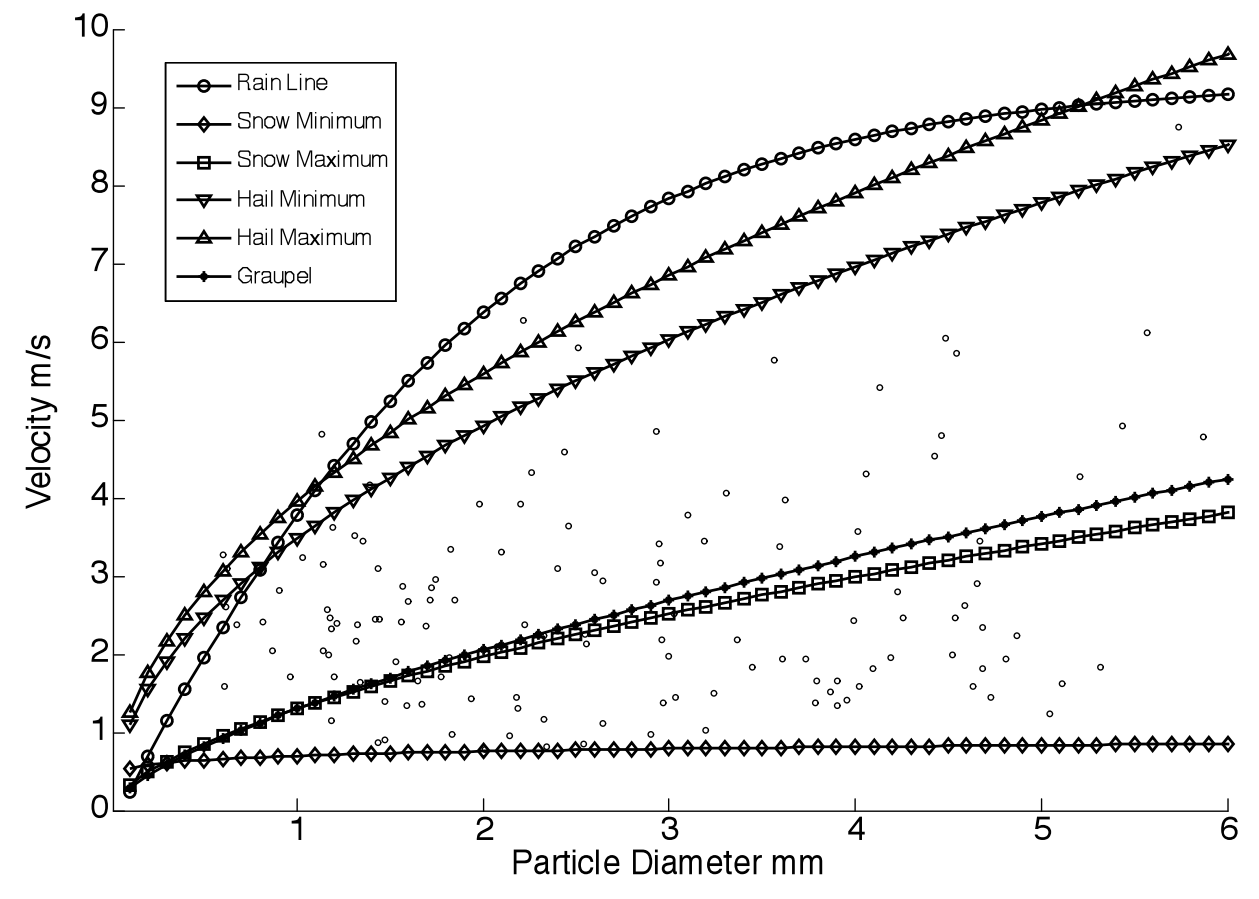

Figure 10. PWS size and velocity measurements in a snow event (transit delay measurements).

It is noted that the best fit curves for previous studies, shown in these plots, were carried out on particles which were unrimed [11] giving the minimum snow curve fit up to heavily rimed particles [12] shown as the maximum snow curve fit and finally graupel [13]. It has been shown [26] that the roughness and hence degree of riming is a major factor in the velocity of such particles. Rimed particles have a surface roughness less than unrimed snow and hence will fall faster.

Much of the data for this snow event is outside of the band defined by these other studies, however this is most likely due to the snow fall being partially melted with high water fraction giving rise to particles falling closer to the rain curve than expected for snow.

It is noted that the data displayed in figures 9 and 10 may include a variety of types, as rimed and unrimed particles were observed during these measurements as well as the wet particles that fall faster than expected in a snow event and this accounts for the variability in the results shown. 


\subsection{Visibility measurement}

Figure 11 shows visibility data collected using the PWS instrument during the period 13:00 on the $24^{\text {th }}$ January 2005 to $00: 10$ on the $28^{\text {th }}$ January 2005 in Utah, USA.

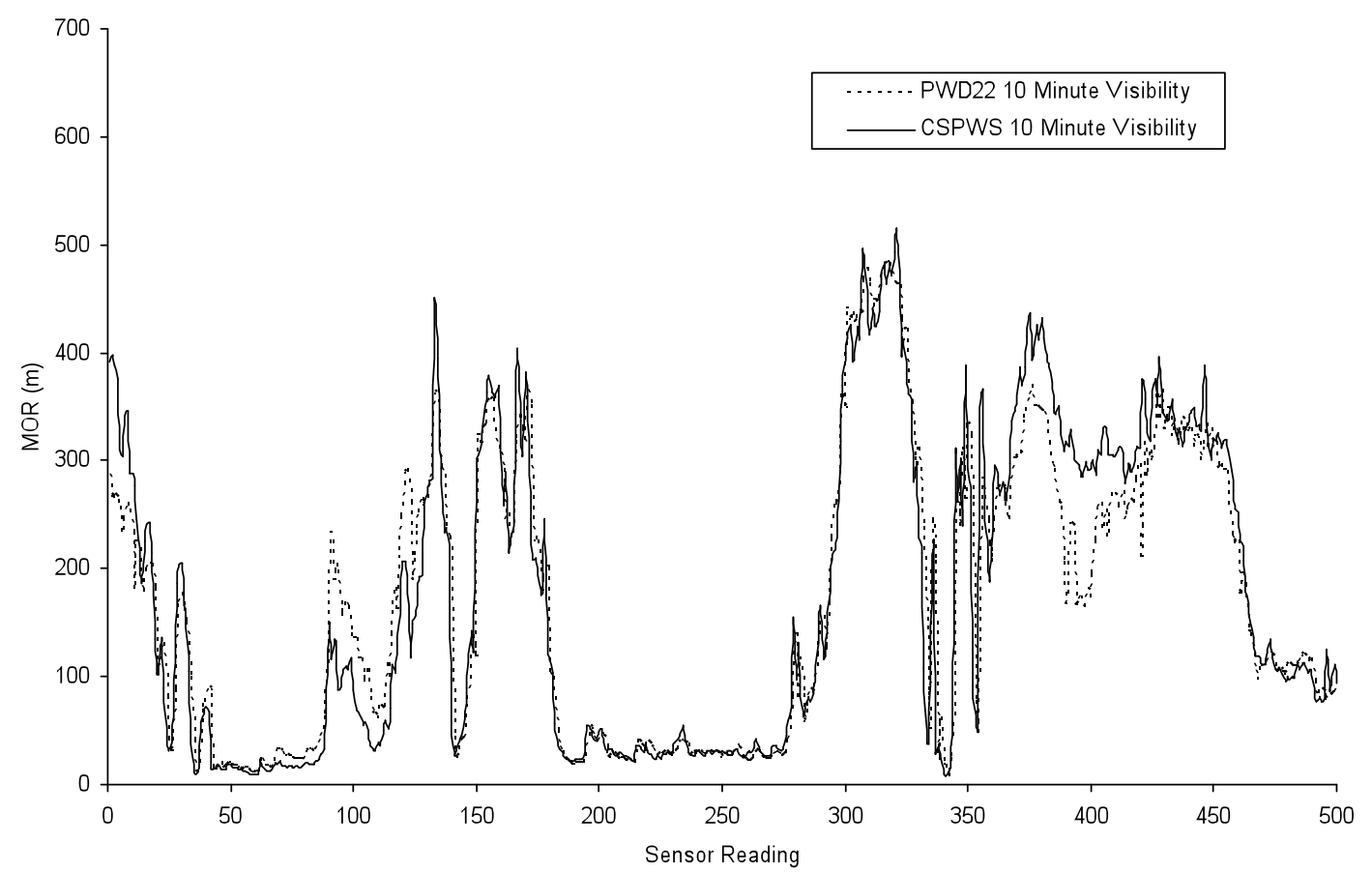

Figure 11. PWS visibility measurement comparison to Vaisala PWD22.

A comparison is made with data taken at the same location using a Vaisala PWD22. The data is evaluated as a 10 min averages taken every 10 minutes for 500 measurements over this evaluation period. It can be seen that the measurements agree well for most of this period though local fluctuations in fog density can lead to some discrepancies.

\section{Conclusions}

In conclusion it is seen that the present weather sensor discussed here is capable of measuring individual particle size and velocity parameters as well as outputting present weather type and rain rate data. The differences in the results of rain and snow are evident from the given data. The particle identification algorithms provide quantifiable amounts of each identified precipitation which can be used the classify events as rain, snow, mixed etc. The sensor is robust and has good accuracy compared to other present weather sensors and can be used in roadside, meteorological and research applications. It also has the added benefits of a 
disdrometer in that size and velocity values can be measured and output as drop size distributions, useful in soil erosion studies. The resulting rain rate values can be used instead of tipping bucket rain gauges and other types of precipitation monitoring equipment. Visibility measurements from the system can easily be used in roadside or aviation applications where measurements of meteorological optical range are critical. 


\section{References}

[1] WMO 1996 Guide to Meteorological Instruments and Methods of Observation (World Meteorological Organization)

[2] WMO 1995 Manual on Codes (World Meteorological Organization)

[3] Laws J O 1941 Measurement of the Fall Velocity of Water-Drops and Raindrops Trans. Amer. Geophys. Union 22 709-721

[4] Gunn R and Kinzer G D 1949 The Terminal Velocity of Fall for Water Droplets in Stagnant Air Journal of Meteorology 6243

[5] Best A C 1950 Q. J. R. Meteorol. Soc. 76 302-311

[6] Brazier-Smith P R 1992 Q. J. R. Meteorol. Soc. 118 749-766

[7] Green A W 1975 Journal of Applied Meteorology 14 1578-1583

[8] Beard K V and Chuang C C 1987 J. Atmos. Sci. 44 1509-1524

[9] Pruppacher H R and Beard K V 1970 Q. J. R. Meteorol. Soc. 96 247-256

[10] Hanesch M, Waldvogel A, Schonhuber M and Randeu W L 1998 Fall Velocity and Shape Parameters of Solid Precipitation Particles Conf. On Cloud Physics 13A.6 (American Meteorological Society) 407-408

[11] Bohm J P 1989 A general equation for the terminal fall speed of solid hydrometeors J. Atmos. Sci. 46 2419-2427

[12] Schefold R, Baschek B, Wuest M and Barthazy E 2002 Fall Velocity and Axial Ratio of Snowflakes Proc. ERAD 2002 84-89

[13] Locatelli J D and Hobbs P V 1974 Fall Speeds and Masses of Solid Precipitation Particles J. Geophys. Res. 79 2185-2197

[14] Auer A H Monthly Weather Rev. 100325

[15] Lozowski E P and Beattle A G 1979 Q. J. R. Meteorol. Soc. 105453

[16] Knight C and Heymsfield A J 1983 J. Atmos. Sci. 401510

[17] Yeh Y and Cummins H 1964 Localised Fluid Measurements with a HeNe Laser Spectrometer Appl. Phy. Lett. 4 176-178

[18] Farmer W M 1972 Measurement of Particle Size, Number Density and Velocity Using a Laser Interferometer Appl. Opt. 11 2603-2612

[19] Durst F, Melling A and Whitelaw J H 1976 Principles and Practice of Laser Doppler Anemometry (London: Academic Press) (ISBN 0122252500)

[20] Durst F and Eliasson B 1975 Properties of Laser Doppler Signals and their Exploitation for Particle Size Measurements Proc. LDA Symp. (Copenhagen) 475477

[21] Wigley G 1978 The Sizing of Large Droplets by Laser Anemometry J.Phys. E: Sci. Instrum. 11 639-642 
[22] Haugen P, Hayes E I, Han Von Benzon H 1994 Size and Velocity Measurements of Large Drops in Air and in a Liquid-Liquid Two-Phase Flow by the Phase-Doppler Technique Part. Part. Syst. Charact. 11 63-72

[23] Nakatani N and Oshio T 1993 Rev. Sci. Instrum. 64 331-337

[24] Hess C F and Wood C P 1994 Part. Part. Syst. Charact. 11 107-113

[25] Lin S M, Waterman D R and Lettington A H 2000 Meas. Sci. Technol. 11 L1-L4

[26] Hanesch M 1999 Fall Velocity and Shapes of Snowflakes (Thesis - Zurich: Swiss Federal Institute of Technology) 